\title{
EFFECT OF AMOUNT OF GRAFTED CNT ON CARBON FIBER ON INTERFACIAL SHEAR STRENGTH BETWEEN CARBON FIBER AND POLYAMIDE RESIN BY MICRODROPLET TEST
}

\author{
KAZUTO TANAKA, TOSHIKI TAKENAKA, TSUTAO KATAYAMA, YUSUKE MORITA, \\ KIMITAKA WATANABE \& MASATAKA KAWAGUCHI \\ Department of Biomedical Engineering, Doshisha University, Japan
}

\begin{abstract}
Carbon Fiber Reinforced Thermoplastics (CFRTP) are expected to be used more in the automobile industry because they could reduce carbon dioxide emissions by improving fuel consumption for engine/hybrid vehicles and extend the driving mileage for electric vehicles. For fiber reinforced composite materials, it is important to control the fiber/matrix interfacial shear strength (IFSS). Recently, carbon nanotubes (CNT) are being applied to CFRP as a reinforcement material because of their outstanding mechanical, electric and thermal properties - especially as a technique for grafting CNTs on the surface of carbon fibers has been developed and CNT grafted carbon fibers show higher fiber/matrix IFSS than carbon fibers. To optimize the fiber/matrix IFSS, the effect of the amount of grafted CNT on carbon fiber on the fiber/matrix IFSS has to be clarified. In this study, the fiber/matrix IFSSs between Polyamide 6 (PA6) and CNT grafted carbon fiber with different amounts of grafted CNT which were prepared using the Ni plating technique were clarified by a microdroplet test. Under the conditions of the Ni plating time of $30 \mathrm{~s}$ and $60 \mathrm{~s}$, the fiber/matrix IFSS was lower than the conditions of the Ni plating time of $5 \mathrm{~s}$ because the resin was not inserted into the fiber/matrix interface due to the aggregation of CNTs, which was related to surface roughness of carbon fiber. Under the conditions of the Ni plating time of $5 \mathrm{~s}$, the best fiber/matrix IFSS was obtained.
\end{abstract}

Keywords: carbon nanotubes, carbon fiber, PA6, CNT grafted carbon fibers, amount of CNT, fiber/matrix interfacial shear strength, microdroplet test.

\section{INTRODUCTION}

Carbon Fiber Reinforced Thermoplastics (CFRTP), which have high specific strength and stiffness, and a short production cycle time, are focused on in the automobile industry. It is important to reduce the weight of the car body in order to reduce carbon dioxide emissions, improve fuel economy, and extend the continuous travel distance of electric vehicles. For fiber reinforced composite materials, it is important to control the fiber/matrix interfacial shear strength (IFSS), since their mechanical properties are influenced not only by the strength of reinforcing fiber and matrix resin, but also by the fiber/matrix IFSS.

Carbon nanotubes (CNTs) have excellent mechanical properties such as high strength, high rigidity, and high heat resistance, therefore recently their applications for composite materials had been attempted. Deposition technique of CNTs on carbon fiber surface has been developed and the fiber/matrix IFSS of CNT grafted carbon fibers has been evaluated [1]. CNT grafted carbon fibers show higher fiber/matrix IFSS than carbon fibers [2]-[6]. It has been reported that this higher fiber/matrix IFSS is due to the anchoring effect of grafted CNT on carbon fiber. To optimize the fiber/matrix IFSS, the effect of the amount of grafted CNT on carbon fiber on the IFSS has to be clarified. Microdroplet test is widely used to assess the fiber/matrix IFSS. In this study, different amounts of CNT were grafted on carbon fiber using carbon fibers with different Ni plating times, and the fiber/matrix IFSS between Polyamide 6 (PA6) and CNT grafted carbon fiber was evaluated by a microdroplet test to optimize the amount of CNTs on the surface of carbon fiber. 


\section{SPECIMEN AND EXPERIMENTAL METHOD}

\subsection{Materials}

PAN-based spread yarn (24K, width 23 mm, Nippon Tokushu Fabric Inc.) was used for carbon fiber. For a catalyst of CNT deposition, Ni particles were plated by electrolytic Ni plating as shown in Fig. 1 with a current density of $0.13 \mathrm{~mA} / \mathrm{mm}^{2}$ and plating times of $5 \mathrm{~s}$, $30 \mathrm{~s}$ and $60 \mathrm{~s}$. A Watt bath having the composition shown in Table 1 was used as the plating solution. Untreated carbon fibers are referred to as $\mathrm{CF}$, and Ni-plated carbon fibers under each condition are referred to as Ni5-CF, Ni30-CF and Ni60-CF respectively, and are collectively referred to as Ni-CF. A scanning electron microscope (SEM, JSM-6390LT, JEOL) was used to observe the surface of Ni-CF. Polyamide 6 (PA6, Ube Industries, 1015B) was used as the matrix for the microdroplet test.

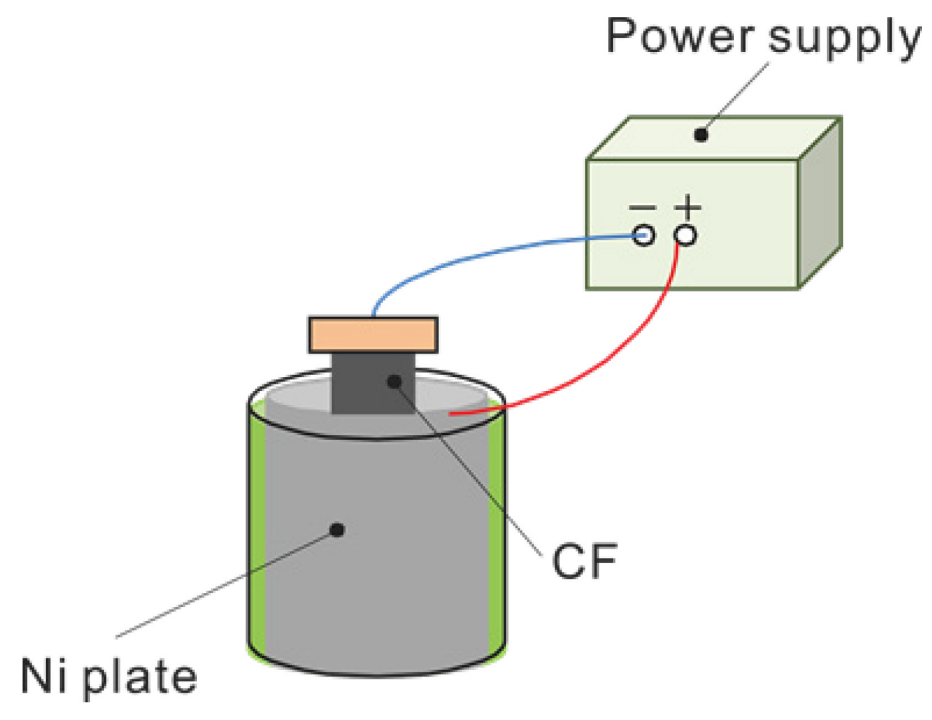

Figure 1: Schematic drawing of Ni plating method.

Table 1: Electrolytic Ni plating solution.

\begin{tabular}{|c|c|c|}
\hline \multicolumn{2}{|c|}{ Solution } & Concentration \\
\hline Nickel sulfate & $\mathrm{NiSO}_{4} \cdot 6 \mathrm{H}_{2} \mathrm{O}$ & $240 \mathrm{~g} / \mathrm{L}$ \\
\hline Nickel chloride & $\mathrm{NiCl}_{2} \cdot 6 \mathrm{H}_{2} \mathrm{O}$ & $45 \mathrm{~g} / \mathrm{L}$ \\
\hline Boracic acid & $\mathrm{H}_{3} \mathrm{BO}_{3}$ & $30 \mathrm{~g} / \mathrm{L}$ \\
\hline
\end{tabular}




\subsection{CNT deposition on carbon fiber}

CNTs were deposited on Ni5-CF, Ni30-CF and Ni60-CF by the Chemical Vapor Deposition (CVD) method using a chemical vapor deposition system (MPCVD-70, microphase). Ar gas was used as the carrier gas, $\mathrm{C}_{2} \mathrm{H}_{5} \mathrm{OH}$ was used as the carbon source, the deposition temperature was $600^{\circ} \mathrm{C}$, and the deposition time was $30 \mathrm{~min}$. Hereinafter, these are referred to as CNT-Ni5-CF, CNT-Ni30-CF and CNT-Ni60-CF, respectively, and collectively referred to as CNT-CF. A field-emission scanning electron microscope (FE-SEM, JSM-7001F, JEOL) was used to observe the surface of CNT-CF. For CNT-CF under each condition, the deposition amount of CNT was analyzed by using an analytical balance (Shimadzu Corporation, AUD220D), and the weight difference was calculated before and after CNT deposition divided by the Ni-CF weight. The divided value was calculated as the CNT deposition weight ratio. These four types of carbon fiber bundles, CF, CNT-Ni5-CF, CNT-Ni30-CF and CNT-Ni60-CF, were used for the sample.

\subsection{Microdroplet test}

The fiber/matrix IFSS was evaluated by the microdroplet test. Fig. 2 shows a schematic drawing of a prepared microdroplet specimens. One single carbon fiber was taken out from CF, CNT-Ni5-CF, CNT-Ni30-CF and CNT-Ni60-CF, and fixed to an aluminum frame, then a microdroplet specimen was prepared by dipping into melted PA6 resin on a hot plate heated at $260^{\circ} \mathrm{C}$. By pulling it out at a speed of $50 \mu \mathrm{m} / \mathrm{s}$ by a high-speed dip coater (DC4300, Aiden Co., Ltd.). The melted PA6 resin was adhered to the surface of carbon fiber to form microdroplets. The microdroplet test was conducted by a small tabletop tester (EZ-SX, Shimadzu, maximum load $500 \mathrm{~N})$ at the displacement speed of $2.0 \times 10^{-6} \mathrm{~m} / \mathrm{s}(0.12 \mathrm{~mm} / \mathrm{min})$ with a self-made blade as shown in Fig. 3 . The force to pull the fiber from the microdroplet $\left(F_{\max }\right)$ was measured to calculate the fiber/matrix IFSS using eqn (1)

$$
\tau=\frac{F_{\max }}{\pi d l}
$$

where $\tau$ is the fiber/matrix IFSS, $d$ is the diameter of fiber, $l$ is the embedded length of the microdroplet, respectively.

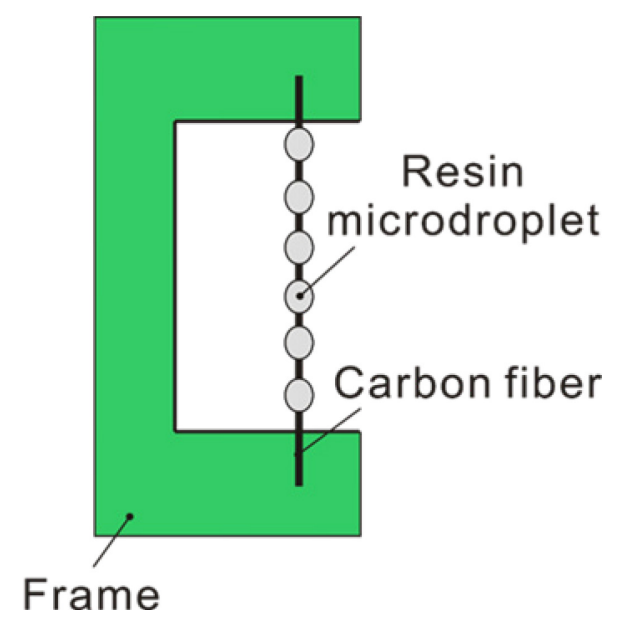

Figure 2: Schematic drawing of CF/PA6 microdroplet specimen. 


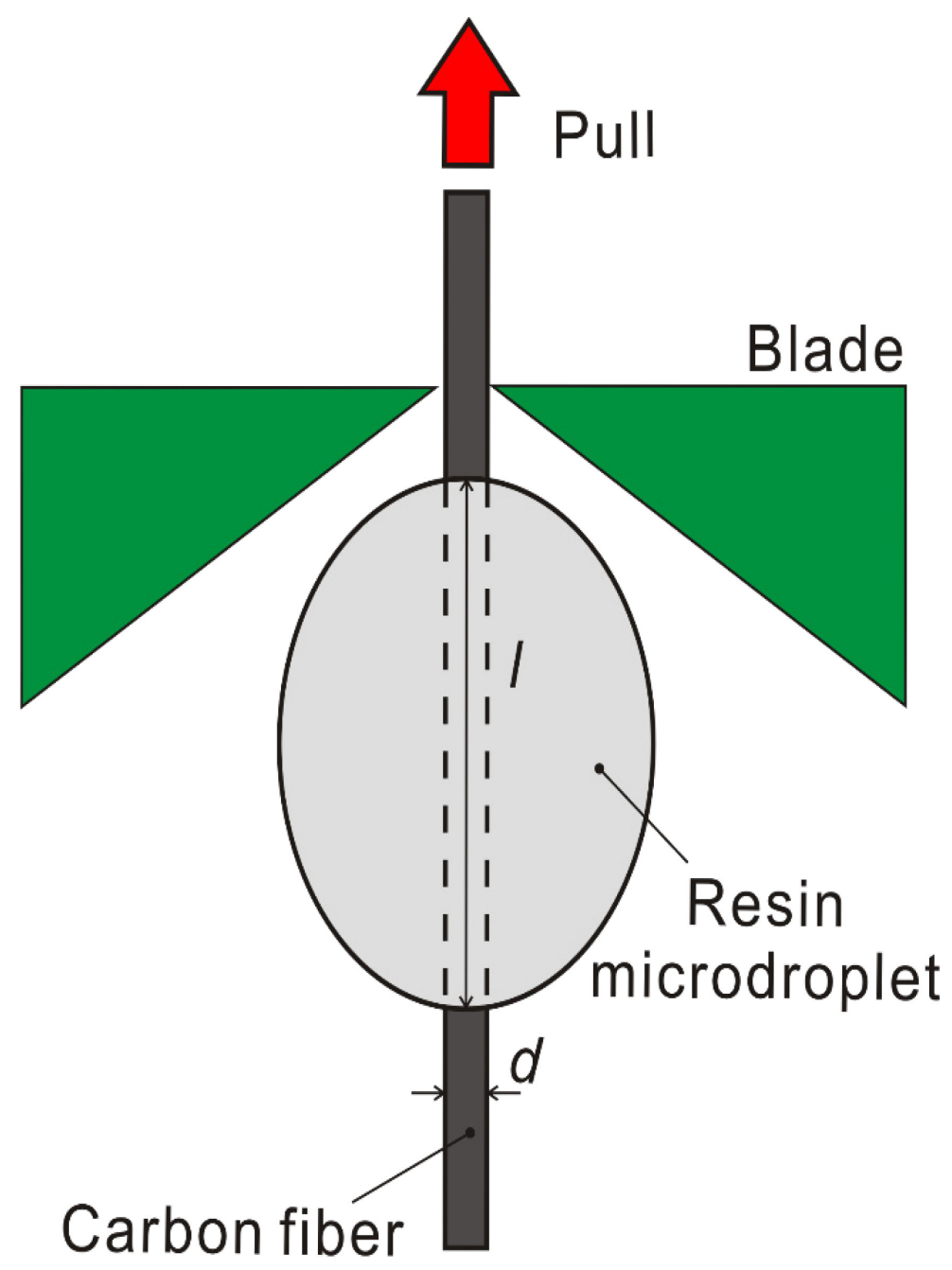

Figure 3: Schematic drawing of the microdroplet test.

\section{RESULTS AND DISCUSSION}

\subsection{Observation of Ni plated and CNT grafted carbon fibers}

Fig. 4 shows SEM images of Ni-CF with different Ni plating times. White dots are plated Ni particles. The number of Ni particles existing on the carbon fiber surface increased as the plating time increased.

Fig. 5 shows FE-SEM images of CNT-CF and Fig. 6 shows the ratio of CNT deposition weight on carbon fiber to $\mathrm{CF}$. The longer the Ni plating time, the larger the ratio of CNT deposition weight is. There is a correlation between the number of catalyst particles and the number of grafted CNTs, and it has been reported that the greater the number of catalyst particles is, the greater the deposition amount of CNTs is [7]. In this study, similar tendency can be observed and CNT-Ni60-CF has the most grafted CNTs. 
High Performance and Optimum Design of Structures and Materials IV 55

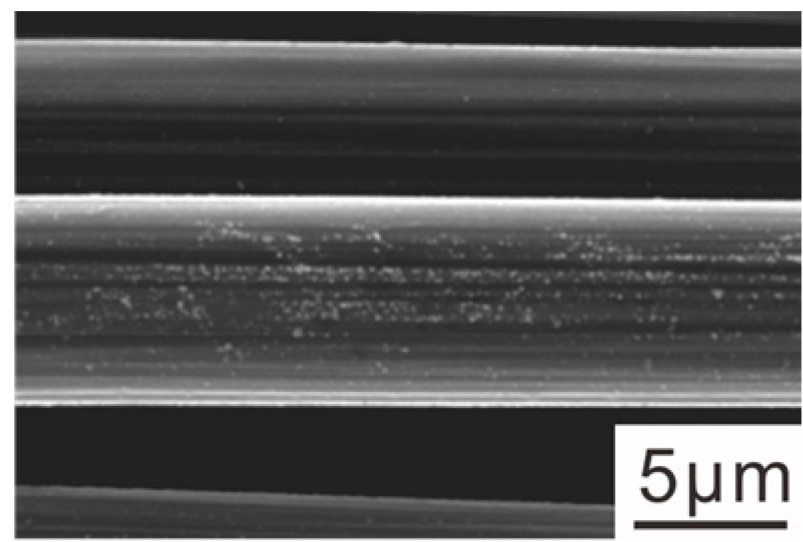

(a)

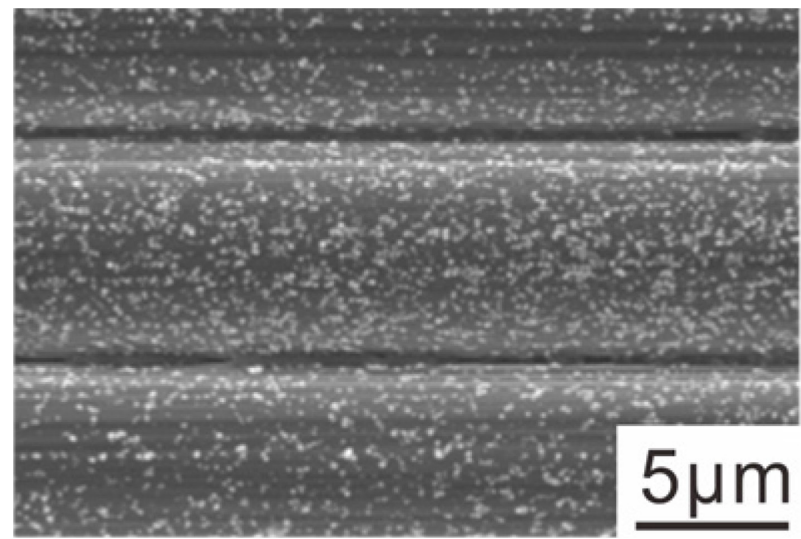

(b)

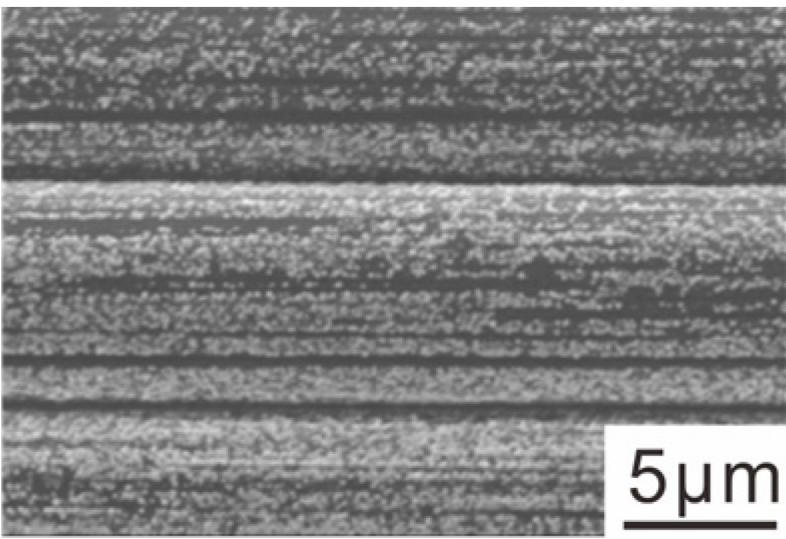

(c)

Figure 4: SEM images of Ni-CF. (a) Ni5-CF; (b) Ni30-CF; and (c) Ni60-CF. 


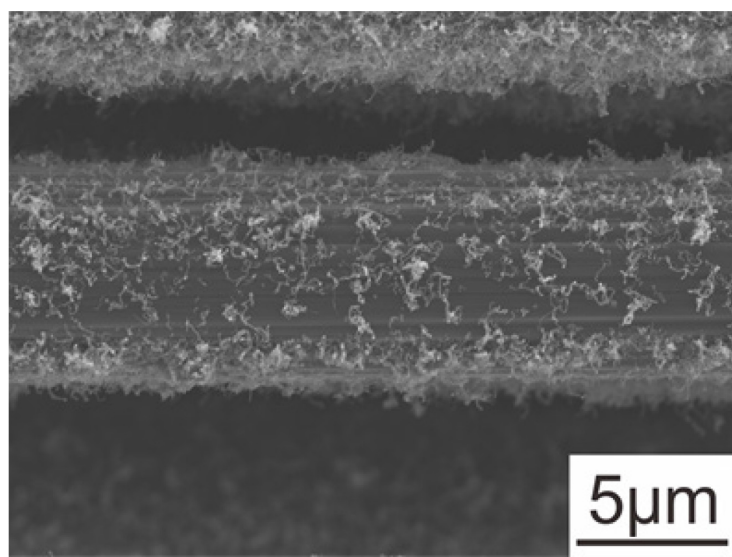

(a)

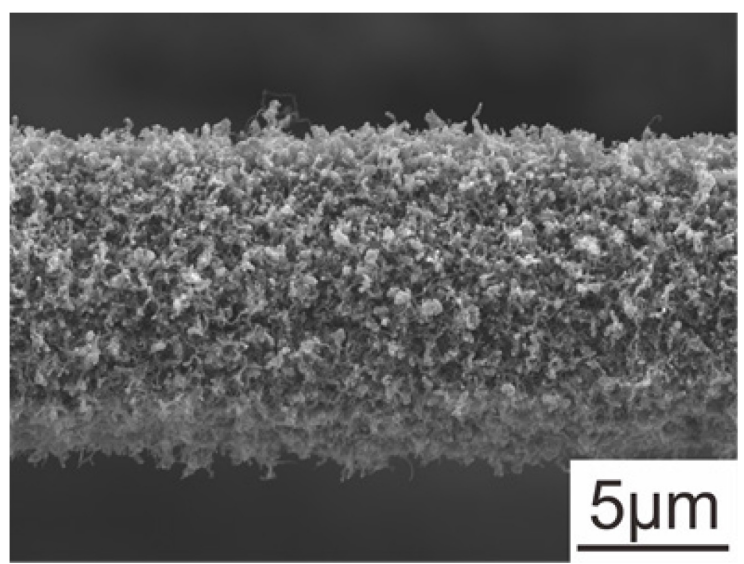

(b)

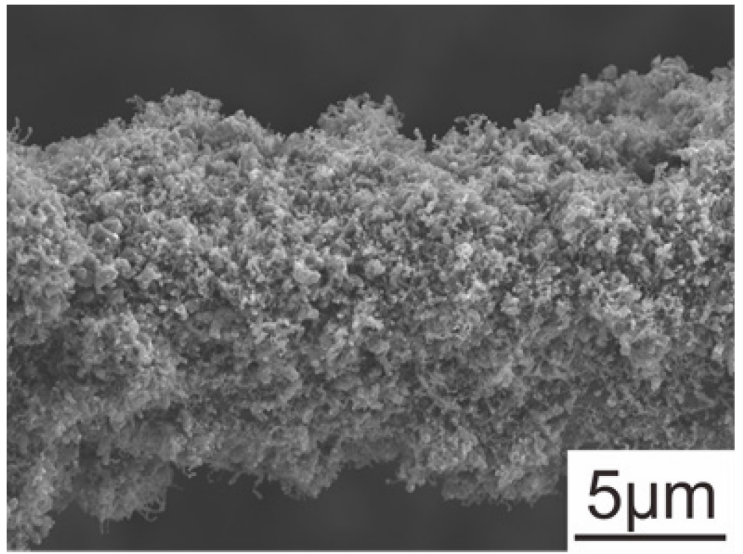

(c)

Figure 5: FE-SEM images of CNT-CF. (a) CNT-Ni5-CF; (b) CNT-Ni30-CF; and (c) CNT-Ni60-CF. 


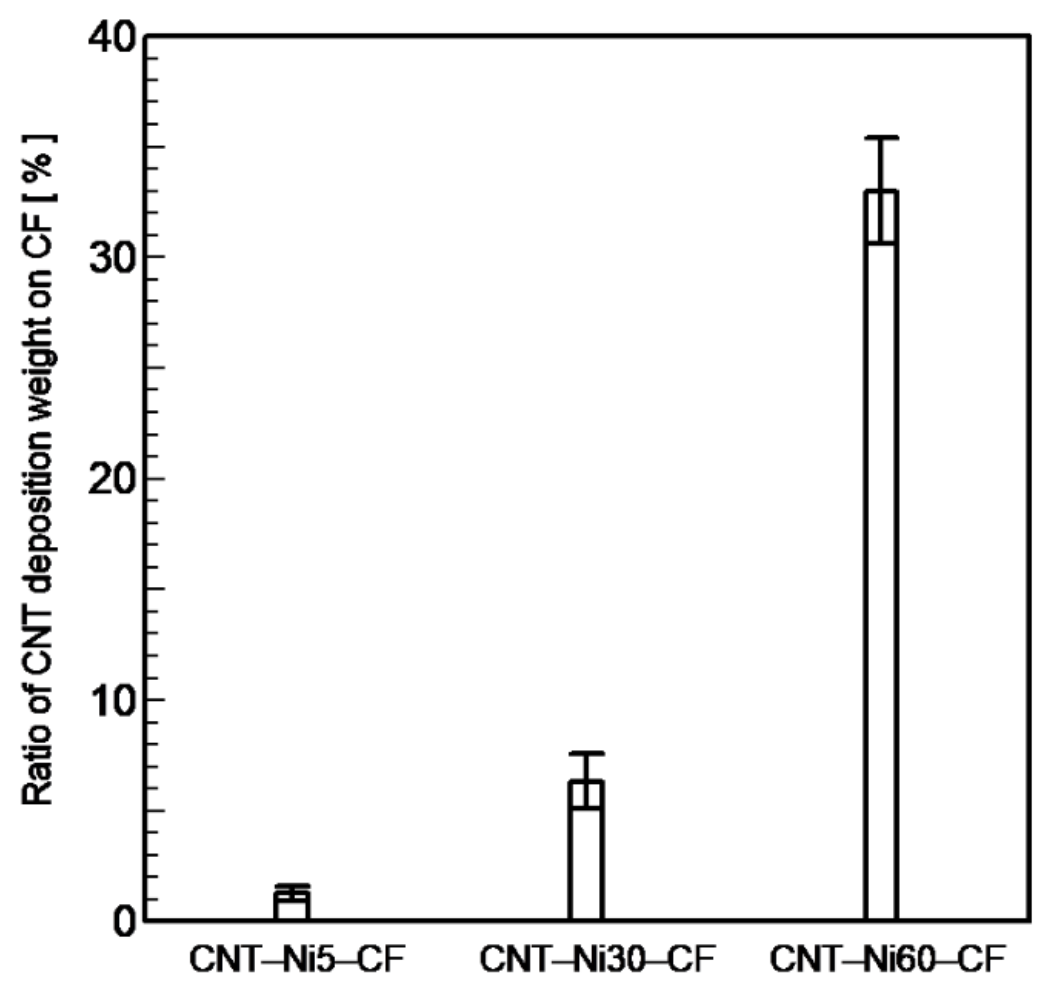

Figure 6: Ratio of CNT deposition weight on carbon fiber to $\mathrm{CF}(\mathrm{N}=4$, mean \pm S.D.).

\subsection{Fiber/matrix interfacial shear strength (IFSS)}

Fig. 7 shows the fiber/matrix IFSSs of CF, CNT-Ni5-CF, CNT-Ni30-CF and CNT-Ni60-CF obtained by the microdroplet test. CNT-Ni5-CF, CNT-Ni30-CF and CNT-Ni60-CF showed higher fiber/matrix IFSS than CF. CNT-Ni5-CF showed the highest fiber/matrix IFSS among them. In CNT-Ni30-CF and CNT-Ni60-CF, no significant difference was found in the fiber/matrix IFSS. Fig. 8 shows the SEM images of microdroplet specimen after debonding. For CNT-Ni5-CF, as pointed by yellow dotted circle in Fig. 8, residual resin was observed on the fracture surface of carbon fiber near meniscus. These results indicate that the interfacial adhesive strength between CNT-Ni5-CF and PA6 matrix is so strong that the fracture occurs at the weaker part of the matrix, rather than the interface of fiber and resin. It has been reported that grafted CNT on carbon fiber can enhance the surface roughness of the carbon fiber. Surface roughening is beneficial for increasing the contact area between the fiber and the matrix and for improving the frictional component of adhesion [8]. Furthermore, when CNT is grafted on the surface of carbon fiber, the impregnation property of the resin into the carbon fiber bundle is improved due to improving surface roughness of the carbon fiber, and the resin is impregnated into the gap of the CNT. As a result, mechanical locking force is obtained and the higher fiber/matrix IFSS can be obtained [9]. In this study, under the condition of Ni plating time of $5 \mathrm{~s}$, the mechanical locking force was considered to be obtained by the impregnation of the resin between the grafted CNTs, and the higher fiber/matrix IFSS was obtained. 
On the other hand, for CNT-Ni30-CF and CNT-Ni60-CF, aggregated CNTs were observed on the fractured surface of the carbon fiber near meniscus and the surface of carbon fiber was not covered with resin. It is considered that the resin is not sufficiently impregnated even at the fiber/matrix interface due to the aggregation of CNTs, and the resin was impregnated only near the outermost layer of CNT. When the resin microdoplet was pulled out, fracture occurred at the resin part near the outermost layer of CNT, and the CNT near the innermost layer which was not impregnated with resin remained on the carbon fiber. Therefore, the interfacial adhesion between fibers and PA6 matrix was not enough and cannot be effectively improved. It has been reported that CNT aggregates in CNT grafted carbon fibers become the starting point of fracture [10]. In this study, under the conditions of plating time of $30 \mathrm{~s}$ and $60 \mathrm{~s}$, CNT aggregated due to excessive grafted CNT on carbon fiber, and resin impregnation was not sufficient compared to CNT-Ni5-CF. This is considered to be the reason why the fiber/matrix IFSS of CNT-Ni30-CF and CNT-Ni60-CF was lower than that of CNT-Ni5-CF.

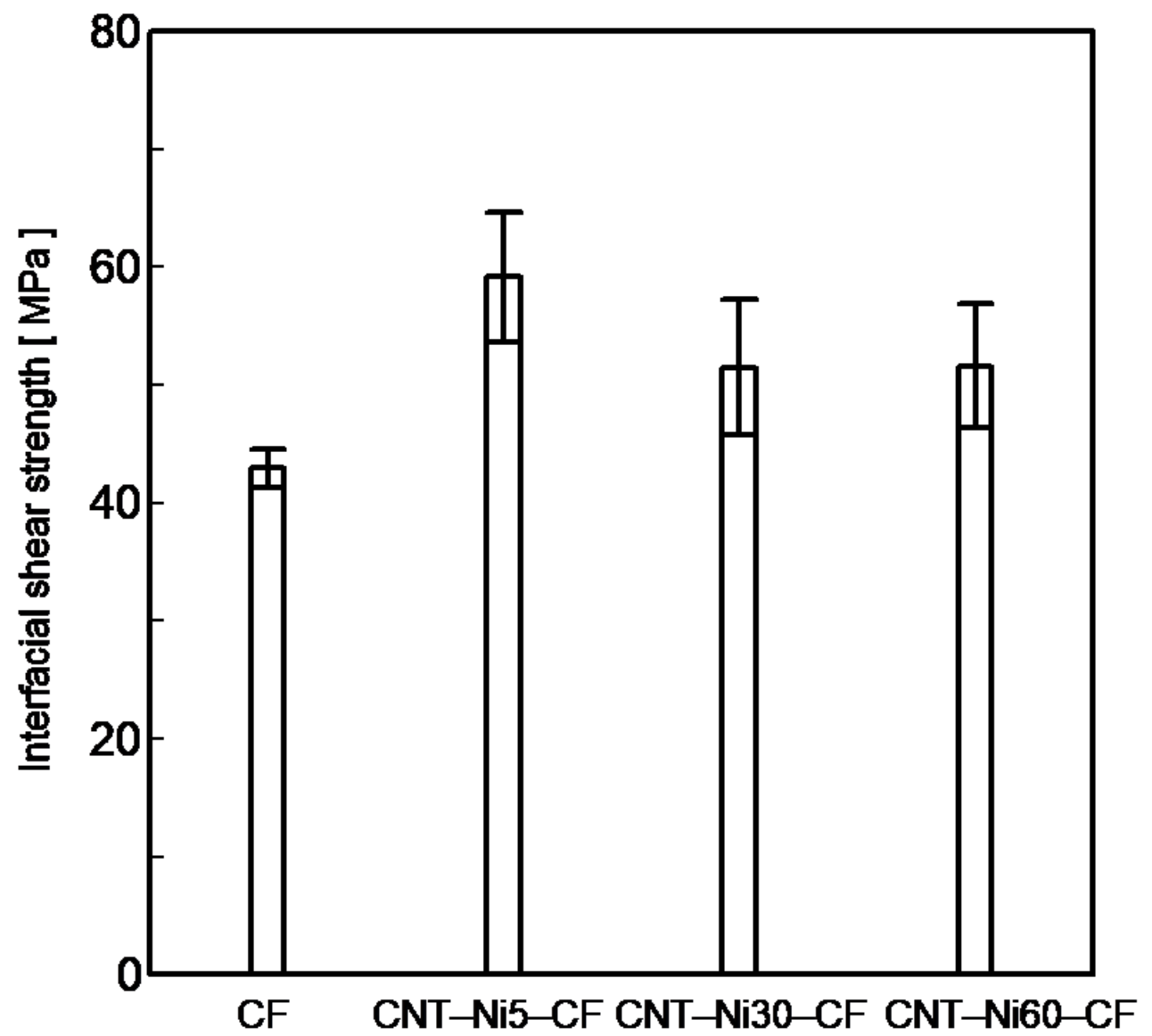

Figure 7: Interfacial shear strength of $\mathrm{CNT}-\mathrm{CF}$ over plating time $(\mathrm{N}=5$, mean \pm S.D.). 

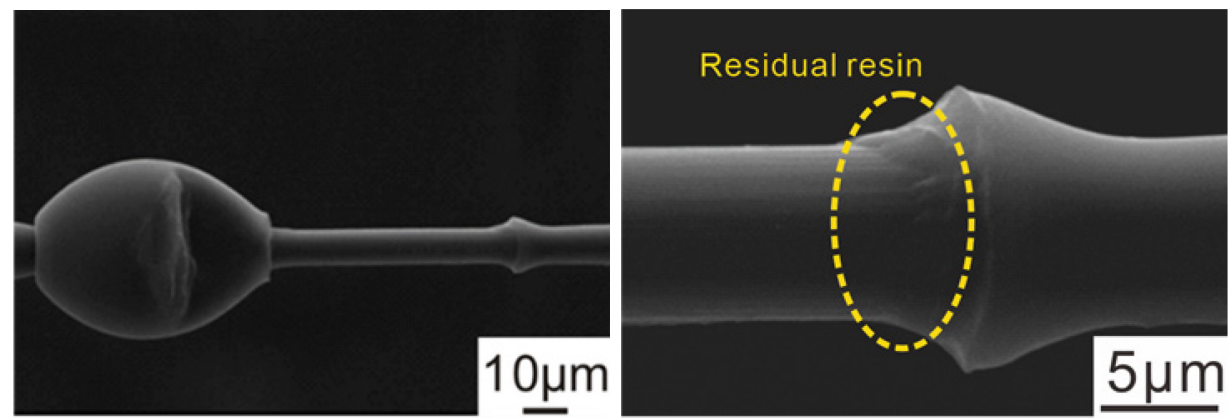

(a)
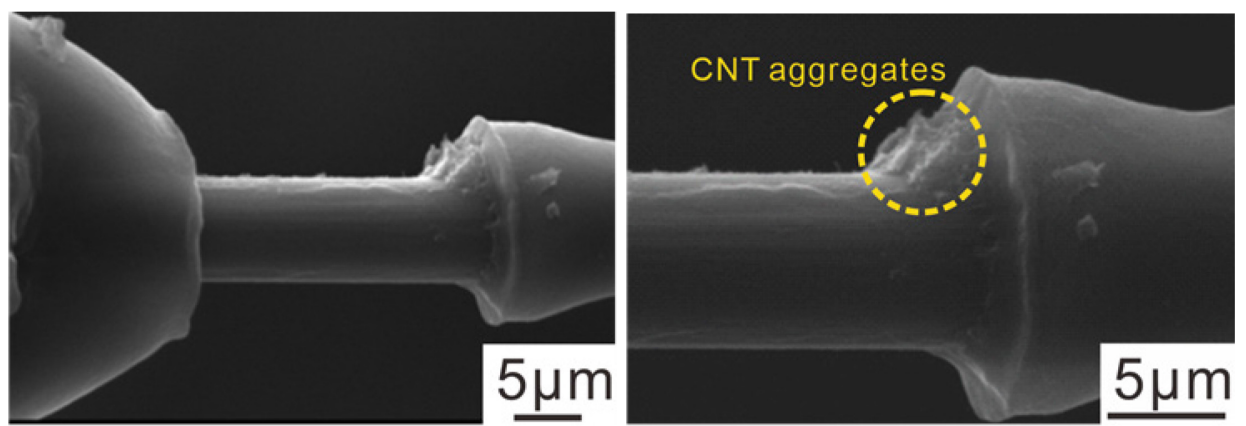

(b)
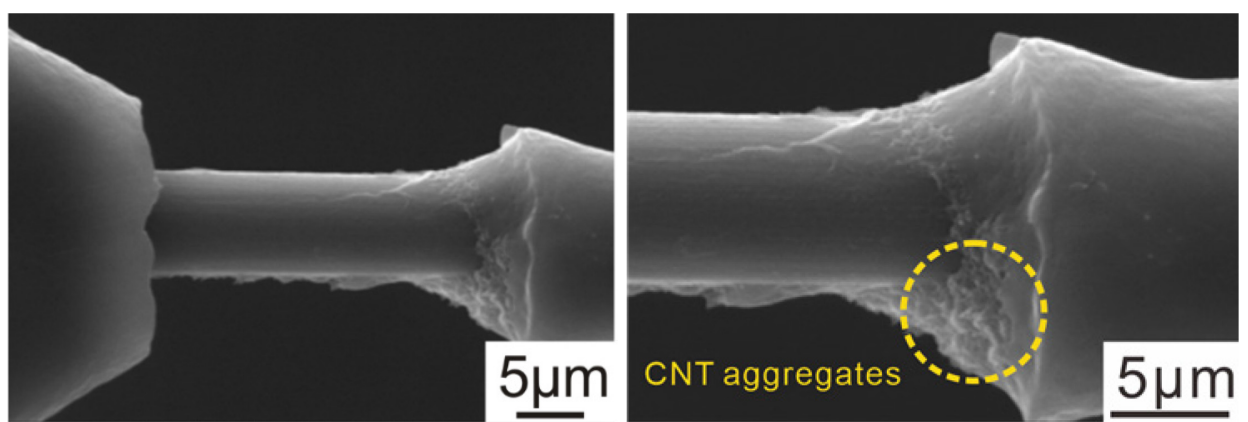

(c)

Figure 8: $\quad$ SEM images of microdroplet test: (a) CNT-Ni5-CF; (b) CNT-Ni30-CF; and (c) CNT-Ni60-CF.

\section{CONCLUSION}

Carbon fibers with different amounts of grafted CNTs were prepared using carbon fibers with different Ni plating times, and the fiber/matrix IFSS between PA6 and CNT grafted carbon fiber was evaluated by microdroplet tests. The effect of the amount of CNTs on the surface of carbon fiber influencing the IFSS between PA6 and CNT grafted carbon fiber was clarified. The investigation yielded the following conclusions.

1. The longer the Ni plating time, the larger the ratio of CNT deposition weight is. In this study, CNT-Ni60-CF has the most grafted CNTs. 
2. Grafted CNTs on carbon fibers is effective in improving the fiber/matrix IFSS with PA6. Under the conditions of plating time of $5 \mathrm{~s}$, the best fiber/matrix IFSS was obtained due to the higher interfacial adhesive strength between CNT-Ni5-CF and PA6 matrix. Considering from the fact that the residual resin was observed on the surface of CNT-Ni5-CF after microdroplet test, the fracture occurs at the weaker part of the matrix, rather than the interface of fiber and resin.

\section{ACKNOWLEDGEMENTS}

This work was partially supported by KAKENHI(Japan Society for the Promotion of Science, Grant-in-Aid for Scientific Research (B))(19H02031) and a research project on "Research and Development Center for Advanced Composite Materials" of Doshisha University and MEXT (the Ministry of Education, Culture, Sports, Science and Technology, Japan) - Supported Program for the Strategic Research Foundation at Private Universities, 2013-2017, the project S1311036.

\section{REFERENCES}

[1] Sager, R.J. et al., Effect of carbon nanotubes on the interfacial shear strength of T650 carbon fiber in an epoxy matrix. Composites Science and Technology, 69, pp. 898-904, 2009.

[2] Tanaka, K., Kawabe, M. \& Katayama, T., Evaluation of mechanical properties of press and injection hybrid molded products using CNT Grafted plain fiber fabric at rib roots. Journal of the Society of Materials Science, Japan, 68(8), pp. 636-642, 2019.

[3] Tanaka, K., Okumura, Y., Katayama, T. \& Morita, T., Effect of carbon nanotubes deposition form on carbon fiber and polyamide resin interfacial strength. Journal of the Society of Materials Science, Japan, 65(8), pp. 586-591, 2016.

[4] Chena, J., Xu, H., Liu, C., Mi, L. \& Shen, C., The effect of double grafted interface layer on the properties of carbon fiber reinforced polyamide 66 composites. Composites Science and Technology, 168, pp. 20-27, 2018.

[5] Pozegic, T.R. et al., Development of sizing-free multi-functional carbon fiber nanocomposites. Composites: Part A, 90, pp. 306-319, 2016.

[6] Li, Q., Church, J.S., Naebe, M. \& Fox, B.L., Interfacial characterization and reinforcing mechanism of novel carbon nanotube - Carbon fibre hybrid composites. Carbon, 109, pp. 74-86, 2016.

[7] Cheung, C.L., Kurtz, A., Park, H. \& Lieber, C.M., Diameter-controlled synthesis of carbon nanotubes. The Journal of Physical Chemistry B, 106, pp. 2429-2433, 2002.

[8] Yao, X., Gao, X., Jiang, J., Xu, C., Deng, C. \& Wang, J., Comparison of carbon nanotubes and graphene oxide coated carbon fiber for improving the interfacial properties of carbon fiber/epoxy composites. Composites: Part B, 132, pp. 170-177, 2018.

[9] Yumitori, S., Arao, Y., Tanaka, T., Naito, K., Tanaka, K. \& Katayama, T., Increasing the interfacial strength in carbon fiber/polypropylene composites by growing CNTs on the fibers. Computational Methods and Experimental Measurements, 55, pp. 275-284, 2013.

[10] Zhao, M. et al., Layer-by-layer grafting CNTs onto carbon fibers surface for enhancing the interfacial properties of epoxy resin composites. Composites Science and Technology, 154, pp. 28-36, 2018. 